\title{
BMJ Open Children's toothache is becoming everybody's business: where do parents go when their children have oral pain in London, England? A cross-sectional analysis
}

\author{
Vanessa Elaine Muirhead, ${ }^{1}$ Zahidul Quayyum, ${ }^{2}$ Donal Markey, ${ }^{3,4}$ \\ Sally Weston-Price, ${ }^{1}$ Annette Kimber, ${ }^{3}$ Wayne Rouse, ${ }^{3}$ Cynthia M Pine ${ }^{1}$
}

To cite: Muirhead VE,

Quayyum Z, Markey D, et al. Children's toothache is becoming everybody's business: where do parents go when their children have oral pain in London, England? A crosssectional analysis. BMJ Open 2018;8:e020771. doi:10.1136/ bmjopen-2017-020771

\section{- Prepublication history for} this paper is available online. To view these files, please visit the journal online (http://dx.doi. org/10.1136/bmjopen-2017020771).

Received 23 November 2017 Revised 11 January 2018 Accepted 15 January 2018

Check for updates

${ }^{1}$ Centre for Dental Public Health and Primary Care, Institute of Dentistry, Queen Mary University of London, London, UK

${ }^{2}$ Centre for Primary Care and Public Health, Blizard Institute, Queen Mary University of London, London, UK

${ }^{3}$ Dental, Optometry and Pharmacy Commissioning, NHS England London Region, London, UK

${ }^{4}$ Children \& Young People Programme, Healthy London Partnerships, London, UK

Correspondence to Dr Vanessa Elaine Muirhead; v.muirhead@qmul.ac.uk

\section{ABSTRACT}

Objectives To assess the number of parents who visited community pharmacies in London seeking pain medications for their children's pain and specifically for oral pain, to identify which health services parents contacted before their pharmacy visit and to estimate the cost to the National Health Service (NHS) when children with oral pain who visit pharmacies also see health professionals outside dentistry.

Design A cross-sectional study.

Setting 1862 pharmacies in London in November 2016January 2017.

Participants Parents, carers and adolescents purchasing over-the-counter pain medications or collecting pain prescriptions for children (0-19 years).

Brief intervention A survey administered by pharmacy staff to participants and a guidance pack.

Main outcome measures The number of parents who visited pharmacies seeking pain medications for their children's pain and oral pain and the number of parents who contacted health professionals outside dentistry before their pharmacy visit. Estimated costs of visits by children with oral pain to health professionals outside dentistry.

Results One in two (951) pharmacies participated collecting information from 6915 parents seeking pain medications for their children. The majority $(65 \%)$ of parents sought pain medications to relieve their children's oral pain. Only $30 \%$ of children with oral pain had seen a dentist before the pharmacy visit, while $28 \%$ of children had seen between one and four different health professionals. The cost to the NHS of children contacting health professionals outside dentistry was £36 573, extrapolated to an annual cost of $£ 373288$. Replicating these findings across all pharmacies in England could mean that the NHS spends an estimated $£ 2.3$ million annually when children with oral pain inappropriately use multiple health services.

Conclusion Most parents who visited pharmacies for children's pain medications in London sought pain medications for children's oral pain. Children's inappropriate contact with multiple health services when they have oral pain adds significant costs to the NHS.

\section{Strengths and limitations of this study}

- Our study is the first to show that most parents in London who sought pain medications from community pharmacies did so to relieve their children's oral pain.

- The study strengths are that it captured information from more than half of all of the pharmacies in London and from nearly 7000 parents and that it is the first study to provide estimates of the cost to the National Health Service when parents of children with oral pain inappropriately contact multiple health professionals outside dentistry.

- The study limitations include the extrapolation of cost estimations that assumed minimal seasonal variations in the number of parents who visited pharmacies across the year and similar patterns for parents visiting the community pharmacies who did not participate in the study.

\section{INTRODUCTION}

Nearly 2 million patients visit one of the 11688 community pharmacies in England every day, exceeding the 1 million patients seen by general practitioners (GPs) daily. ${ }^{12}$ Under the current National Health Service (NHS) community pharmacy contractual framework, pharmacies dispense medicines and give patients self-care advice about managing minor ailments and long-term illnesses. ${ }^{3}$ The number of patients using community pharmacies, the demands on GPs and inappropriate patient attendances in accident and emergency (A\&E) departments are major drivers for increasing the role of pharmacies. ${ }^{45}$ The independent review of Community Pharmacy Clinical Services and the General Practice Forward View in 2016 also emphasised the need to develop their scope. ${ }^{67}$ One of these developments has been the increasingly 
recognised public health role for community pharmacies. ${ }^{8}$ Tooth decay (dental caries) is a significant public health problem despite improvements in children's oral health over the past five decades. ${ }^{9}$ A quarter of children aged 5 years in England still have tooth decay in their primary (baby) teeth and approximately one in five (21\%) children aged 12 years have tooth decay in their adult teeth. ${ }^{10}$ While medical GP registration for children is almost universal with school children seeing a doctor two to three times a year, ${ }^{11}$ only $58 \%$ of children in England and $49 \%$ of children aged $0-19$ years in London had visited a dentist in the past 12 months in $2016 .{ }^{12}$ This low uptake of dental services occurs despite national guidelines recommending that 12 months should be the maximum time interval between dental visits for children. ${ }^{13}$

A painful mouth or a toothache is one of the most serious impacts of tooth decay, which could trigger parents to visit pharmacies for over-the-counter (OTC) pain medications or prescribed analgesics. ${ }^{14}$ However, this cannot be quantified because no studies have assessed if parents visit pharmacies when their children have pain in their mouth and/or a tooth, defined as oral pain. The low uptake of dental services could mean that parents and children with oral pain visit pharmacies and contact other health professionals. We know that children with oral pain are seen by GPs ${ }^{15}$ and in A\&E departments, ${ }^{16}$ but do parents also contact other health professionals outside dentistry? Understanding the cost implications and the appropriateness of children with oral pain seeing other health professionals rather than dental professionals is crucial in this climate of resource scarcity. This study aimed to address these key questions by capturing real-time information from pharmacy staff and parents who visited pharmacies in London. The objectives were to (1) assess the number of parents who visited community pharmacies in London seeking pain medications for their children's pain and, specifically, for oral pain; (2) quantify the health professionals and services that parents of children with oral pain contacted before going to the pharmacy; and (3) estimate the cost to the NHS when children with oral pain who visit pharmacies also see health professionals outside dentistry.

\section{METHODS \\ Design}

This was a cross-sectional study surveying parents, carers and adolescents who visited community pharmacies in London during a 10-week period in November 2016January 2017. This exploratory study was aligned to a previous public health community pharmacy campaign that ran for 6 weeks. We extended the data collection period by 4 weeks to include the weeks before and after Christmas-the New Year holidays. Community pharmacy staff used a survey that was part of a brief intervention developed by academic researchers at Queen Mary University of London in partnership with Healthy London Partnership. ${ }^{17}$ The survey was anonymous.
Box 1 The eight questions that community pharmacy staff asked parents purchasing over-the-counter (OTC) pain medications or collecting pain prescriptions for their children

1. Does the child have pain in their mouth and/or a tooth?

2. Does the child have swelling around their throat or eye, a rash, high temperature (fever), loss of appetite, (signs of systemic disease), uncontrolled bleeding or trauma to their teeth and jaws?

3. Has the child already seen a dentist about their pain?

4. Does the child have a regular dentist?

5. Has the child seen another health professional or health service about their dental pain?

6. Does the child have: a toothache?

7. Does the child have: pain from a newly erupting tooth?

8. Does the child have: a painful mouth ulcer?

\section{Participants}

The participants were parents, carers or adolescents who were specifically purchasing OTC pain medications or collecting prescriptions for pain medications for children or adolescents aged 0-19 years. Pain medications included any paediatric paracetamol or ibuprofen oral suspension, sachets or tablets.

\section{Intervention}

The brief intervention developed by the researchers included an online survey that pharmacy staff administered to parents and carers and a guidance pack and fact sheets about common oral conditions for community pharmacy staff. ${ }^{17}$ The survey consisted of eight questions developed by the researchers from National Institute of Health and Care Excellence and Scottish Dental Clinical Effectiveness Programme guidance on managing dental pain $^{18}{ }^{19}$ (box 1). The pharmacy staff accessed the online survey from pharmacy computers, laptops, tablets or smartphones in real time at the point of parent contact.

The questions also asked parents about the cause of the pain (ie, oral pain or other pain type), whether the child had signs and symptoms of a systemic disease that would warrant immediate signposting to an A\&E department ${ }^{20}$ and whether they had already contacted their regular dentist or another health professional. Parents who reported that their child currently had a pain in their mouth and/or a tooth also confirmed the type of pain based on the types of oral pain that children commonly experience: toothache, pain from a newly erupting tooth (teething) or a mouth ulcer. ${ }^{21}$

The supporting guidance pack and fact sheets gave community pharmacies information about signs and symptoms of oral pain and guidance about how to advise and signpost parents after they had administered the survey. ${ }^{17}$

\section{Procedure}

The brief intervention was delivered as part of a mandatory public health campaign. ${ }^{22}$ We invited the 1862 community pharmacies in London and their pharmacy counter staff, dispensers, pharmacy technicians, preregistration 
pharmacists and pharmacists to participate. Pharmacy staff approached any parents, carers or adolescents who were purchasing or collecting any paediatric pain medication regardless of the child's pain complaint. They asked all of the participants the eight survey questions shown in box 1 and recorded their responses on the online survey. Community pharmacies also collected information about the age of the child, the day of the week, the time of the visit to the pharmacy and the type of medication that parents were seeking (eg, prescriptions or OTC medications).

\section{Outcomes}

The main outcomes were the number and percentage of parents who visited a community pharmacy seeking pain medications for their children for any pain complaint and for oral pain and the number and percentage of parents who visited other health professionals and services before going to the pharmacy. The secondary pain outcomes were the type of oral pain (ie, toothache, pain from a newly erupted tooth or a painful mouth ulcer) and the number and percentage of children who had signs and symptoms of a dental emergency: swelling around their throat or eye, uncontrolled bleeding, trauma to their teeth and jaws or signs or symptoms of systemic disease (eg, rash, high temperature and loss of appetite). ${ }^{23}$ To calculate costs, we used the unit costs from the Personal Social Services Research Unit 2016 report $^{24}$ and from the Department of Health National Schedule of Reference costs. ${ }^{25}$ The cost of GP out-of-hours services was based on the 2014 National Audit Office report ${ }^{26}$ and an inflationary adjustment factor (1.33) obtained from the hospital and community health services pay and price index used to convert costs to 2016 costs. ${ }^{24}$

\section{Statistical analysis}

We used STATA (V.12) to analyse the data reporting for the main outcomes and the secondary pain outcomes. For the cost-analysis, we multiplied the number of children who contacted a health professional or a service outside dentistry before visiting a pharmacy by the standardised unit costs to calculate the total cost to the NHS of children using other health services during the 10-week period. We then extrapolated the costs for a 52-week period assuming minimal seasonal variations in the number of parents who visited a pharmacy for pain medications for their children across the year based on Prescription Cost Analysis data. ${ }^{27}$ Our final cost estimation extrapolated the annual costs assuming that all of the 1862 pharmacies in London participated.

\section{Patient and stakeholder involvement}

The NHS England London Region Patient Leadership Board for Dentistry, Optometry and Pharmacy and members of the Local Pharmaceutical Committee (LPC) reviewed the eight questions, the design of the brief intervention and the guidance pack and fact sheets. We incorporated their feedback into the final design of the study. Members of the LPC also piloted the survey before its launch.

\section{RESULTS}

\section{Community pharmacy and parent characteristics}

Fifty-one per cent $(\mathrm{n}=951)$ of community pharmacies participated across London during the 10-week period. The pharmacies collected data from 6915 parents who visited them to purchase or to collect pain medications for their children. This number varied by pharmacy ranging from 1 to 73 parents with an average of seven parents visiting each pharmacy.

\section{Parents who sought relief for their children's oral pain}

Oral pain was the most common reason for parents to seek pain medications from pharmacies for their children over 10 weeks. Nearly two-thirds $(65 \%)$ of the parents sought pain relief for a child who had oral pain at the time of the visit to the pharmacy (table 1). Forty-one per cent of children had toothache, $20 \%$ had pain from a newly erupting tooth and $15 \%$ had a painful mouth ulcer. More teenagers had toothache and painful mouth ulcers than younger children $\left(\chi^{2}\right.$ for trend test; $\left.\mathrm{P}<0.001\right)$, while more preschool children had teething pain from erupting teeth $\left(\chi^{2}\right.$ for trend test; $\left.\mathrm{P}<0.001\right)$ (table 1$)$. Saturdays and Sundays were the peak days for parents to visit pharmacies for pain medication for children's oral pain.

Table 1 Number (\%) of parents who had a child with oral pain, toothache and pain from a newly erupting tooth or a painful mouth ulcer by the child's age

\begin{tabular}{|ccccc}
\hline $\begin{array}{l}\text { Child and pharmacy } \\
\text { visit characteristics }\end{array}$ & $\begin{array}{l}\text { Number (\%) of } \\
\text { children with any } \\
\text { oral pain }\end{array}$ & $\begin{array}{l}\text { Number (\%) of } \\
\text { children who had } \\
\text { toothache }\end{array}$ & $\begin{array}{l}\text { Number (\%) of children } \\
\text { who had pain from an } \\
\text { erupting tooth }\end{array}$ & $\begin{array}{l}\text { Number (\%) of children } \\
\text { who had a painful mouth } \\
\text { ulcer }\end{array}$ \\
\hline $\begin{array}{l}\text { Age of child (years) } \\
0-3\end{array}$ & $956(56.1)$ & $362(21.4)$ & $821(48.6)$ & $110(6.5)$ \\
\hline $4-7$ & $1149(58.1)$ & $720(36.5)$ & $290(14.8)$ & $322(16.3)$ \\
\hline $8-11$ & $917(66.5)$ & $665(48.4)$ & $125(9.1)$ & $255(18.5)$ \\
\hline $12-15$ & $756(76.5)$ & $534(54.1)$ & $55(5.6)$ & $207(21.0)$ \\
$16-19$ & $647(85.7)$ & $471(63.1)$ & $72(9.6)$ & $150(20.0)$ \\
\hline All ages & $4425(65.1)$ & $2752(40.6)$ & $1363(20.2)$ & $1044(15.4)$ \\
\hline
\end{tabular}


Seventy per cent of parents who had children with oral pain were purchasing OTC pain medications. This also varied by the child's age. Eighty-one per cent of parents who had children aged 0-3 years purchased OTC pain medications compared with $70 \%$ of parents with children aged 4-7 years, $64 \%$ of parents with children aged $8-11$ years, $65 \%$ of parents with children aged $12-15$ years and $68 \%$ of parents with children aged 16-19years.

Nearly 1 in $10(n=591)$ of all children had signs and symptoms indicating a dental emergency and community pharmacy staff signposted them to emergency services.

\section{Parents who contacted health professionals and services before going to the pharmacy}

Only $30 \%$ of the children with oral pain had seen a dentist before they visited the pharmacy. Contact with dentists also varied by the oral pain type and the age of the child. Forty-five per cent of children who had a toothache had seen a dentist before they went to the pharmacy compared with only $7 \%$ of children who had pain from an erupting tooth and $7 \%$ who had a mouth ulcer. Only a quarter of children with a toothache aged 0-3years had seen a dentist compared with $44 \%$ of children aged 4-7years, $49 \%$ of children aged $8-11$ years, $48 \%$ of children aged $12-15$ years and $42 \%$ of children aged $16-19$ years $\left(\chi^{2}\right.$ test for trend; $\mathrm{P}=0.03$ ).

Twenty-eight per cent of children with oral pain had contacted health professionals and health services outside dentistry before visiting the pharmacy (table 2). GPs $(14 \%)$ were the most common health professionals. Children had also visited health visitors, practice nurses, school nurses and GP out-of-hours services before going to the pharmacy. Four per cent of children had contacted a secondary care A\&E department, an urgent care centre or the NHS 111 telephone advice service. Table 2 shows the multiple contacts that the parents of children with oral pain had with health professionals and services outside dentistry seeing between one to four different health professionals before their pharmacy visit.

\section{The costs of children with oral pain seeing health professionals outside dentistry}

Table 3 shows the cost to the NHS when children with oral pain see health professionals outside dentistry before going to a pharmacy. To estimate the cost of inappropriate health contacts (overuse), we excluded children with oral pain who had signs of systemic disease or a dental emergency that could have warranted a GP or an A\&E visit or parent who had contacted the NHS 111 telephone advice service. Contacts with GPs (£16 668) and with NHS walk-in/urgent care centres (£3135) were the most costly single contacts made by children who had oral pain. Contacts with GPs represented $59 \%$ of the total primary care costs, while NHS walk-in/urgent care centres contacts represented $78 \%$ of the total secondary care costs. Multiple contacts with other health professionals outside dentistry contributed an additional $£ 4402$ to produce a total cost to the NHS of $£ 36573$. This
Table 2 Number (\%) of children with oral pain who had seen a dentist and other health professionals and services before their pharmacy visit

\begin{tabular}{lc}
\hline $\begin{array}{l}\text { Contacts with health } \\
\text { professionals or services }\end{array}$ & $\begin{array}{c}\text { Number (\%) of children } \\
\text { who had oral pain }\end{array}$ \\
\hline $\begin{array}{l}\text { One contact with a health professional before their } \\
\text { pharmacy visit }\end{array}$ & $1310(29.5)$ \\
\hline Dentist & $617(13.8)$ \\
\hline GP & $56(1.3)$ \\
\hline Practice nurse & $39(0.9)$ \\
\hline Health visitor & $113(2.5)$ \\
\hline School nurse & $10(0.2)$ \\
\hline GP out of hours & $205(4.6)$ \\
\hline Another pharmacy & $31(0.7)$ \\
\hline A\&E & $57(1.3)$ \\
\hline NHS walk-in/urgent care & \\
centre & $93(2.1)$ \\
\hline NHS 111 (telephone advice) & \\
\hline
\end{tabular}

Multiple contacts with health professionals outside dentistry before their pharmacy visit

\begin{tabular}{ll} 
GP and practice nurse & $11(0.25)$ \\
GP and school nurse & $11(0.25)$ \\
GP and health visitor & $3(0.07)$ \\
$\begin{array}{l}\text { GP out of hours and school } \\
\text { nurse }\end{array}$ & $1(0.02)$ \\
$\begin{array}{l}\text { GP and GP out of hours } \\
\text { Practice nurse and health } \\
\text { visitor }\end{array}$ & $3(0.07)$ \\
$\begin{array}{l}\text { Practice nurse and school } \\
\text { nurse }\end{array}$ & $1(0.02)$ \\
$\begin{array}{l}\text { Health visitor and school nurse } \\
\text { GP, GP out of hours, health } \\
\text { visitor }\end{array}$ & $1(0.02)$ \\
$\begin{array}{l}\text { GP, health visitor and practice } \\
\text { nurse }\end{array}$ & $2(0.02)$ \\
$\begin{array}{l}\text { GP, practice nurse and school } \\
\text { nurse }\end{array}$ & $3(0.07)$ \\
$\begin{array}{l}\text { GP, health visitor and school } \\
\text { nurse }\end{array}$ & $1(0.02)$ \\
$\begin{array}{l}\text { GP, health visitor, practice } \\
\text { nurse and school nurse }\end{array}$ & $1(0.02)$ \\
$\begin{array}{l}\text { GP and A\&E } \\
\text { A\&E, GP and school nurse }\end{array}$ & $3(0.07)$ \\
\hline
\end{tabular}

*https://www.england.nhs.uk/urgent-emergency-care/nhs-111/ A\&E, accident and emergency; GP, general practitioner.

represents the cost of inappropriate health contacts and service overuse by children with oral pain during the 10-week period (table 3). We extrapolated these costs for the 52-week period to yield an estimated annual cost for the NHS of $£ 190178$. We finally calculated the cost to the NHS of parents who could be visiting all of the 
Table 3 Calculated and estimated costs to the NHS of children with oral pain contacting health professionals and health services outside dentistry before their pharmacy visit

\begin{tabular}{|c|c|c|c|}
\hline $\begin{array}{l}\text { Contact with health professionals } \\
\text { outside dentistry }\end{array}$ & $\begin{array}{l}\text { Total cost over the } 10- \\
\text { week study period }(£)\end{array}$ & $\begin{array}{l}\text { Extrapolated costs for } \\
52 \text { weeks for the study } \\
\text { pharmacies (£) }\end{array}$ & $\begin{array}{l}\text { Extrapolated costs for } \\
52 \text { weeks and } 100 \% \\
\text { pharmacy participation }(£)\end{array}$ \\
\hline \multicolumn{4}{|c|}{ One contact with a health professional or service outside dentistry } \\
\hline Practice nurse† & 2408 & 12522 & 24551 \\
\hline Health visitor† & 2067 & 10748 & 21074 \\
\hline GP out of hours $\ddagger^{*}$ & 904 & 4701 & 9217 \\
\hline Accident and emergency (A\&E) $\S^{*}$ & 882 & 4586 & 8992 \\
\hline NHS walk-in/urgent care centre§ & 3135 & 16302 & 31965 \\
\hline $\begin{array}{l}\text { Subtotal for a single health professional } \\
\text { contact outside dentistry }\end{array}$ & 32166 & 167263 & 328356 \\
\hline
\end{tabular}

Two contacts with a health professional or service outside dentistry

\begin{tabular}{|c|c|c|c|}
\hline GP and practice nurse $\dagger$ & 869 & 4519 & 8860 \\
\hline GP and health visitor $†$ & 267 & 1388 & 2722 \\
\hline GP and school nurse† & 990 & 5148 & 10094 \\
\hline GP and GP out of hours $† \ddagger$ & 378 & 1966 & 3854 \\
\hline Practice nurse and health visitort & 96 & 499 & 978 \\
\hline Health visitor and school nurse $†$ & 107 & 556 & 1091 \\
\hline GP and A\&E†§ & 156 & 811 & 1591 \\
\hline $\begin{array}{l}\text { Subtotal for two health professional } \\
\text { contacts outside dentistry }\end{array}$ & 2948 & 16140 & 31647 \\
\hline \multicolumn{4}{|c|}{ Three or more contacts with a health professional or service outside dentistry } \\
\hline A\&E, GP and school nurse†§ & 132 & 686 & 1346 \\
\hline GP, health visitor and school nurse $†$ & 143 & 744 & 1458 \\
\hline $\begin{array}{l}\text { GP, health visitor, practice nurse and } \\
\text { school nurse } \dagger\end{array}$ & 186 & 967 & 1896 \\
\hline $\begin{array}{l}\text { Subtotal for three or more health } \\
\text { contacts outside dentistry }\end{array}$ & 1171 & 6089 & 11939 \\
\hline Total cost & 36573 & 190178 & 373288 \\
\hline
\end{tabular}

${ }^{*}$ Child reported no signs of systemic disease or a dental emergency that may warrant a GP or A\&E visit.

†Unit costs obtained from the PSSRU Unit Costs of Health and Social Care 2016.

fUnit costs obtained from the National Audit Office 'Out-of-hours GP services in England. London: 2014' report reporting an average cost of $£ 68$ including a 1.33 inflationary factor.

§Unit costs obtained from the National Schedule of reference costs main schedule 2015-2016.

GP, general practitioner; PSSRU, Personal Social Services Research Unit.

pharmacies in London estimated as £373 288: the annual NHS cost of multiple and inappropriate health service use by children with oral pain (table 3 ).

\section{DISCUSSION}

Our study showed that the reason the majority of parents in London seek pain medications for their children from community pharmacies is to relieve their children's oral pain. We possibly underestimated the number of children with oral pain in London, because we used community pharmacies as a means of identifying children and parents. This meant that we only captured the parents who visited community pharmacies during their children's current pain episode. Our extrapolated costs also assumed that the same number of parents would have contacted the community pharmacies (49\%) in London who did not 
participate in the study. However, we did not include children with oral pain whose parents used pain medications that they had previously purchased or medications purchased from supermarkets. We also did not include parents who had children with pain who contacted other health services but not a pharmacy. Our study is the first to capture information from more than half of all of the pharmacies in London demonstrating that thousands of parents are visiting pharmacies every week because their children have oral pain.

Children with oral pain need to see a dentist for a definitive pain diagnosis and to treat the most likely cause of their pain: tooth decay. Toothache occurs when the decay encroaches on the tooth's nerve and blood supply. Not treating a decayed tooth at this stage can result in more pain, abscesses and possible damage to an underlying developing permanent tooth. The fact that only $30 \%$ of children with oral pain had seen a dentist before going to a pharmacy highlights a concerning underuse of dental services. More parents visited pharmacies over the weekend, which could partly explain why some parents had not seen a dentist. Cope $e t a l^{15}$ also found that dental consultations in UK GP practices peaked on Mondays. Parents often find it difficult to access urgent dental care services over the weekend. ${ }^{28}$ Parents might also prioritise getting pain relief using OTC medications if they cannot readily access local dental services. Parents with preschool children also purchased OTC pain medications without seeing a dentist, which mirrors the low dental attendance figures for this age group. Dental service usage data showed that only $23 \%$ of children aged $0-4$ years in London had visited a dentist in the previous 12 months in March 2017. ${ }^{29}$ Dentists often refer younger (precooperative) children with multiple decayed teeth for tooth extractions under general anaesthesia (GA) ${ }^{30}$ However, there are significant waiting times for dental extractions under GA in London. This is common in other areas. For example, a study of hospitals in the northwest of England found that children waited an average of 137 days for a GA tooth extraction appointment. ${ }^{31}$ The preschool children in our study with toothache could be the children experiencing unremitting oral pain while on GA waiting lists, prompting parents to visit a pharmacy for pain relief.

Children with oral pain had not only failed to see a dentist before their pharmacy visit; they had seen GPs and a myriad of other health professionals outside dentistry. Parents may have contacted different health professionals because they were unsure about what services to use or to seek different opinions to resolve their children's oral pain ('doctor-shopping'). ${ }^{32}$ Another possible explanation is that health professionals could have prompted these multiple contacts. Health professionals who have a limited understanding of how to manage children's dental problems might refer children to inappropriate healthcare settings. A qualitative study exploring children who had febrile illnesses found that health professionals rather than parents initiated multiple health contacts, referring parents onward to different health services. ${ }^{33}$ GPs have also described the challenges that they have had managing patients with dental problems, often pressurised by patients to prescribe antibiotics inappropriately. ${ }^{34}$

What are the implications of our study? First, children with oral pain contacting different health professionals clearly demonstrates that oral pain is becoming everybody's business. Better communication between health professionals and integrated care pathways would direct children with oral pain to dental services regardless of what service they contact first. Community pharmacies can also play a key role in oral health promotion by directing children who have obvious dental problems to local dental services rather than to GPs or to A\&E departments. Second, children with oral pain did not visit a dentist before going to the pharmacy and they had toothache commonly caused by tooth decay: a largely preventable disease. Health professionals can support prevention and promote early dental attendance initiatives especially those targeting preschool children such as the recently launched 'Dental Check by 1 ' programme. ${ }^{35}$ This initiative aims to increase the number of children under 2 years who access dental services. Finally, we estimated the potential cost of children with oral pain using multiple health services outside dentistry in London. Replicating these findings across the 11688 community pharmacies in England would equate to an estimated $£ 2.3$ million being spent by the NHS every year on children with oral pain inappropriately using multiple health services outside dentistry. Reducing the inappropriate and multiple contacts that children with oral pain have with other health professionals by encouraging parents to access the "right advice in the right place, first time ${ }^{36}$ could offer considerable cost savings to the NHS.

Our study also raises questions to address in future research. We need to understand why parents who have children with oral pain contact other health professionals first rather than dentists in order to address the barriers families face to obtain urgent dental care for their children.

We also need to explore what other health professionals do when they encounter children with oral pain and what oral health advice they give to parents and children who present with dental problems. This might highlight training needs and clarify steps for clear, consistent pathways for parents and all health professionals when caring for children with oral pain.

\section{CONCLUSION}

Most parents who contacted community pharmacies in London for pain medications for their children in this study sought pain relief for their children's oral pain. Parents tended to underuse dental services while contacting multiple health professionals outside dentistry in both primary and secondary care. Reducing children's inappropriate contact with multiple health services when they have oral pain could have significant cost savings for the NHS. 
Contributors VEM designed the study and brief intervention; she wrote the statistical analysis plan, analysed the data and drafted and revised the paper. She is the guarantor. ZQ advised on the cost analysis and drafted and revised the paper. DM initiated the collaborative project, helped to develop the brief intervention and revised the paper. SW-P helped to develop the brief intervention and revised the draft paper. WR and AK designed the brief intervention, monitored data collection for the survey and revised the draft paper. CMP helped to develop the study design and revised the draft paper.

Funding This research was funded by NHS England London Region. Donal Markey was partly funded by Healthy London Partnerships.

Disclaimer The present paper represents the opinions of the authors and does not necessarily reflect the position of their employers.

Competing interests None declared.

Patient consent Not required.

Provenance and peer review Not commissioned; externally peer reviewed.

Data sharing statement № additional data available.

Open Access This is an Open Access article distributed in accordance with the Creative Commons Attribution Non Commercial (CC BY-NC 4.0) license, which permits others to distribute, remix, adapt, build upon this work non-commercially, and license their derivative works on different terms, provided the original work is properly cited and the use is non-commercial. See: http://creativecommons.org/ licenses/by-nc/4.0/

(C) Article author(s) (or their employer(s) unless otherwise stated in the text of the article) 2018. All rights reserved. No commercial use is permitted unless otherwise expressly granted.

\section{REFERENCES}

1. Jepson M, Salisbury C, Ridd MJ, et al. The 'One in a Million' study: creating a database of UK primary care consultations. Br J Gen Pract 2017;67:e345-51.

2. NHS Digital. National Statistics General Pharmaceutical Services in England: 2006/07 to 2015/16. Leeds, UK: NHS Digital, 2016.

3. National Health Service. National Health Service (Pharmaceutical and Local Pharmaceutical Services) Regulations 2013. UK: National Health Service, 2013.

4. Cowling TE, Cecil EV, Soljak MA, et al. Access to primary care and visits to emergency departments in England: a cross-sectional, population-based study. PLoS One 2013;8:e66699.

5. McHale P, Wood S, Hughes K, et al. Who uses emergency departments inappropriately and when: a national cross-sectional study using a monitoring data system. BMC Med 2013;11:258.

6. Murray R. Independent review of community pharmacy clinical services. UK: NHS England, 2016.

7. NHS England. General practice forward view. UK: NHS England, 2016.

8. Public Health England. Pharmacy: a way forward for public health. Opportunities for action through pharmacy for public health. London, UK: Public Health England, 2017.

9. Murray JJ, Vernazza CR, Holmes RD. Forty years of national surveys: an overview of children's dental health from 1973-2013. Br Dent J 2015;219:281-5

10. Health and Social Care Information Centre. Children's dental health survey executive summary England, Wales and Northern Ireland, 2013. UK: Health and Social Care Information Centre, 2015.

11. Van Dorp F. Consultations with children. InnovaAiT 2011;47:54-61.

12. Health and Social Care Information Centre. NHS Dental Statistics 2015-16: table 4a: number (in thousands) of adult patients seen in the previous 24 months, child patients seen in the previous 12 months and the percentage of the population, at specified dates. UK: NHS Digital, 2016.

13. NICE. Dental recall. Recall interval between routine dental examinations. London: NICE, 2004.
14. Tickle M, Blinkhorn AS, Milsom KM. The occurrence of dental pain and extractions over a 3-year period in a cohort of children aged 3-6 years. J Public Health Dent 2008;68:63-9.

15. Cope AL, Chestnutt IG, Wood F, et al. Dental consultations in UK general practice and antibiotic prescribing rates: a retrospective cohort study. Br J Gen Pract 2016;66:e329-36.

16. Currie CC, Stone SJ, Connolly J, et al. Dental pain in the medical emergency department: a cross-sectional study. J Oral Rehabil 2017;44:105-11.

17. Muirhead V, Weston-Price S, Hurst D, et al. Oral health in community pharmacy. Raising awareness of oral health and pain management for children and young people. London, UK: Healthy London Partnership, Queen Mary University of London, NHS England, 2016.

18. National Institure for Health and Care Excellence. Clinical knowledge summaries: dental abscess. London, UK: National Institure for Health and Care Excellence, 2016.

19. Scottish Dental Clinical Effectiveness Programme. Management of acute dental problems. Guidance for healthcare professionals. Dundee: Scottish Dental Clinical Effectiveness Programme, 2013.

20. Department of Health. Implementing local commissioning for primary care dentistry. Factsheet 7: commissioning out-of-hours services. London, UK: Department of Health, 2006.

21. Tsakos G, Hill K, Chadwick B, et al. Children's Dental Health Survey 2013 report 1: attitudes, behaviours and children's dental health England, Wales and Northern Ireland 2013. Leeds, UK: Health and Social Care Information Centre, 2015.

22. Healthy London Partnership. Oral health in community pharmacy. 2016. https://www.myhealth.london.nhs.uk/healthy-london/latest/ publications/oral-health-community-pharmacy.

23. NHS England. A quick guide: extending the role of community pharmacy in urgent care. UK: NHS England, 2015.

24. Curtis L, Burns A. Unit costs of health and social care 2016. Canterbury: Personal Social Services Research Unit, University of Kent, 2016.

25. Department for Health. Reference cost collection: National schedule of reference costs - year 2015-16 - NHS trust and NHS foundation trusts. London, UK: Department for Health, 2016.

26. National Audit Office. Out-of-hours GP services in England. London: National Audit Office, 2014.

27. NHS Business Service Authority. Prescription Cost Analysis (PCA) data. 2016.

28. Roberts N. GPs face extra workload as last community dental clinic in London closed. GPonline. 2017 https://www.gponline.com/gpsface-extra-workload-last-community-dental-clinic-london-closed/ article/1421824.

29. NHS Business Service Authority. London 12 month access rates by patient borough - 0 to 19 year olds as at March 2017, 2017.

30. Adewale L, Morton N, Blayney M. Guidelines for the management of children referred for dental extractions under general anaesthesia. London: Association of Paediatric Anaesthetists of Great Britain and Ireland, 2016.

31. Goodwin M, Sanders C, Davies G, et al. Issues arising following a referral and subsequent wait for extraction under general anaesthetic: impact on children. BMC Oral Health 2015;15:3.

32. Macpherson AK, Kramer MS, Ducharme FM, et al. Doctor shopping before and after a visit to a paediatric emergency department. Paediatr Child Health 2001;6:341-6.

33. Maguire S, Ranmal R, Komulainen S, et al. Which urgent care services do febrile children use and why? Arch Dis Child 2011;96:810-6.

34. Cope AL, Wood F, Francis NA, et al. General practitioners' attitudes towards the management of dental conditions and use of antibiotics in these consultations: a qualitative study. BMJ Open 2015;5:e008551.

35. Office of Chief Dental Officer England. Step change in Commissioning Dental Check by 1 (DCBy1). Rationale, proposal and plan. 2017 https://hiowldc.org/wp-content/uploads/2017/07/ 20170627-LDN-Assembly-Step-Change-DCBy1-CDOv1.pdf.

36. Loader J. Community pharmacy: helping provide better quality and resilient urgent care. UK: NHS England, 2015. 